\title{
Correlation between traffic density and particle size distribution in a street canyon and the dependence on wind direction
}

\author{
J. Voigtländer ${ }^{1}$, T. Tuch ${ }^{1,2}$, W. Birmili ${ }^{1}$, and A. Wiedensohler ${ }^{1}$ \\ ${ }^{1}$ Leibniz Institute for Tropospheric Research, Leipzig, Germany \\ ${ }^{2}$ UFZ Center for Environmental Research, Department of Human Exposure Research and Epidemiology, Leipzig, Germany
}

Received: 14 February 2006 - Published in Atmos. Chem. Phys. Discuss.: 22 May 2006

Revised: 24 July 2006 - Accepted: 8 September 2006 - Published: 22 September 2006

\begin{abstract}
Combustion of fossil fuel in gasoline and diesel powered vehicles is a major source of aerosol particles in a city. In a street canyon, the number concentration of particles smaller than $300 \mathrm{~nm}$ in diameter, which can be inhaled and cause serious health effects, is dominated by particles originating from this source.

In this study we measured both, particle number size distribution and traffic density continuously in a characteristic street canyon in Germany for a time period of 6 months. The street canyon with multistory buildings and 4 traffic lanes is very typical for larger cities. Thus, the measurements also are representative for many other street canyons in Europe. In contrast to previous studies, we measured and analyzed the particle number size distribution with high size resolution using a Twin Differential Mobility Analyzer (TDMPS). The measured size range was from 3 to $800 \mathrm{~nm}$, separated into 40 size channels.
\end{abstract}

Correlation coefficients between particle number concentration for integrated size ranges and traffic counts of 0.5 were determined. Correlations were also calculated for each of the 40 size channels of the DMPS system, respectively. We found a maximum of the correlation coefficients for nucleation mode particles in the size range between 10 and $20 \mathrm{~nm}$ in diameter.

Furthermore, correlations between traffic and particles in dependence of meteorological data were calculated. Relevant parameters were identified by a multiple regression method. In our experiment only wind parameters have influenced the particle number concentration significantly. High correlation coefficients (up to 0.8 ) could be observed in the lee side of the street canyon for particles in the range between 10 and $100 \mathrm{~nm}$ in diameter. These values are significantly higher than correlation coefficients for other wind directions and other particle sizes. A minimum was found in the luff

Correspondence to: J. Voigtländer

(jensv@tropos.de) side of the street. These findings are in good agreement with theory of fluid dynamics in street canyons.

\section{Introduction}

Particles below $10 \mu \mathrm{m}$ in diameter can be inhaled and deposited in human airways. They may be responsible for serious acute (e.g., allergy or irritation of eyes, nose and throat; Dockery and Pope, 1994; WHO, 2000; Penttinen et al., 2001) and long-term (e.g., cancer or cardiovascular disease; Pope et al., 2002) negative health effects. Since April 1999 the EU directive "Council directive 1999/30/EC of 22 April 1999 relating to limit values for sulphur dioxide, nitrogen dioxide and oxides of nitrogen, particulate matter and lead in ambient air" provides upper limits for $\mathrm{PM}_{10}$. The member states are also obliged to collect data for $\mathrm{PM}_{2.5}$.

The smaller the particles the deeper they can be infiltrated (Oberdoerster et al., 2005). Because of inertial impaction effects, coarse mode particles are mainly deposited in the nasal and the upper bronchial airways (Broday, 2004; Oberdoerster et al., 2005). Because of their greater surface per mass, smaller particles also are more active biologically. Previous studies (Pope et al., 1995; Oberdoerster, 2000) suggest that per unit mass, accumulation mode particles $(0.1-1 \mu \mathrm{m})$ are more toxic than coarse mode particles $(>1 \mu \mathrm{m})$. Penttinen et al. (2001) have shown associations of accumulation mode particles with respiratory diseases, but no associations with coarse mode particles.

Acute health effects of ultrafine particles (UFPs, $<0.1 \mu \mathrm{m}$ ) are still widely discussed. While Peters et al. (1997) found that acute respiratory health effects (asthma) are associated with UFPs other studies did not find similar results (Osunsanya et al., 2001). On the other hand, UFPs can even be taken up into the blood and lymph circulation of the human body (Oberdoerster et al., 2005) and may therefore affect the cardiovascular system directly.

Published by Copernicus GmbH on behalf of the European Geosciences Union. 


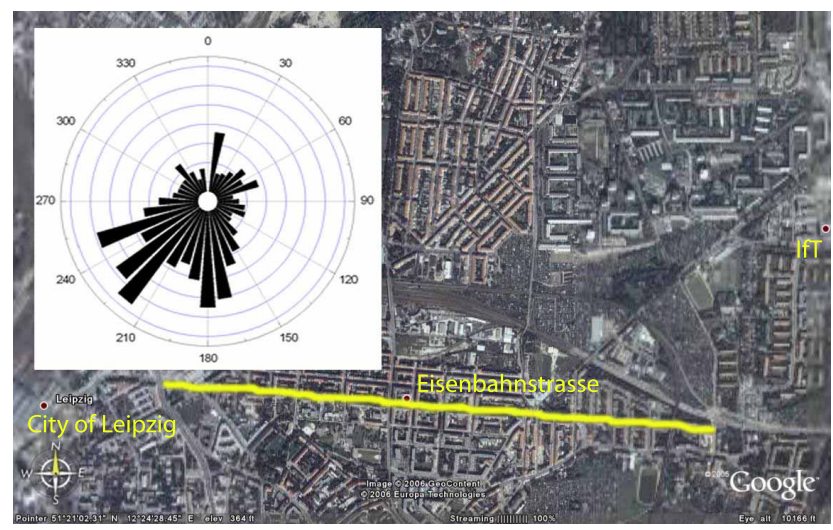

Fig. 1. Map of the measurement site and distribution of the wind direction.

In urban areas, traffic is a major source of aerosol particles. The temporal variation of the particle size distribution is mainly influenced by traffic volume and highest particle concentrations are observed during weekdays (Hussein et al., 2004; Gidhagen et al., 2004).

Exhaust undergoes distinct dilution stages (Zhang and Wexler, 2004). After being emitted, the size distribution of UFPs changed markedly (Zhu and Hinds, 2002). The original size distribution of traffic emitted UFPs is often distributed into two modes (Kittelson et al., 2000) with maxima in the nucleation mode (about $10 \mathrm{~nm}$ ) and in the Aitken mode (about 60-80 nm). Particles in the nucleation mode consists of hydrocarbons, sulphates and water (Kittelson, 1998) and form during dilution and cooling of the exhaust. Particles in the Aitken mode are mainly (diesel) soot particles. With increasing distance and dilution time, the maximum in the nucleation mode shifts to larger particles (Zhu and Hinds, 2002; Ketzel et al., 2004).

Therefore, dilution and observed particle number size distribution depends on atmospheric conditions. Consequently, several previous studies included meteorological parameters (e.g., Charron and Harrison, 2003; Hussein et al., 2006). In these studies, dependencies between the measured particle size distributions and wind parameters and temperature were found, while other meteorological parameters showed no clear dependency.

In this study, we present results of a measurement campaign in a street canyon, located in eastern Germany, which is typical for many other inner city roads in Europe.

In street canyons, the exchange of air mass is reduced and dispersion of pollutants inside the canyon is strongly influenced by the flow field inside the canyon. Many studies focussed on investigations of circulation (e.g., DePaul and Sheih, 1986; Kovar-Panskus et al., 2002; Cheng and $\mathrm{Hu}, 2004$; Lien et al., 2004) and dispersion of pollutants in- side street canyons (e.g., Ketzel et al., 2002; Baik and Kim, 2002; Kim and Baik, 2004; Xie et al., 2005; Nazridoust and Ahmadi, 2006). When the wind flow is perpendicular to the street, a recirculation vortex develops. In regular street canyons (height to width ratio in roughly unity, Vardoulakis et al., 2003), one large vortex can be found. In deeper canyons, a weaker second (and a third) vortex can be observed and modeled (Assimakopoulos et al., 2003) and in wide canyons (height to width ratio below approx. 0.5) no recirculation vortex is observed. Also the shape of the roof influences the circulation inside the canyon (Xie et al., 2005). Additionally, the roof level wind speed also influences the circulation inside the canyon. With increasing wind speed the circulation of the vortex in the canyon also increase (Nazridoust and Ahmadi, 2006). At lower wind velocities, a secondary vortex forms in the canyon, which disappear at high wind speeds (Nazridoust and Ahmadi, 2006). Calculations showed, that circulation is also influenced by thermal effects (Sini et al., 1996).

With high traffic volume at ground level, the circulation leads to higher concentrations in the lee side of the street and lower concentrations in the luff (e.g., Assimakopoulos et al., 2003). At the top of the canyon, turbulent processes mix urban background air into the canyon (Baik and Kim, 2002), which causes a lower concentration at the luff side building.

Previous street canyon studies focussed on total particle number concentrations or particle mass (Gidhagen et al., 2004), only on $\mathrm{NO}_{\mathrm{x}}$ measurements (Kastner-Klein et al., 2003) or did not investigate different wind directions (Virtanen et al., 2006). In our study we measured particle size distributions, traffic volume and meteorological data. We investigated dependencies between particle number size distributions and traffic volume against meteorological data. Because the health effects of UFPs are not sufficiently understood, investigations of particle size distributions inside street canyons and the relationship to their sources are important.

\section{Methods}

\subsection{Site description}

Data presented in this study were measured from October 2003 through March 2004 in a street canyon in Leipzig (Eisenbahnstrasse), Germany. Street canyons with multistory buildings and high traffic volume are typical for European cities. The Eisenbahnstrasse is located in the east part of the city and oriented nearly from west to east (285 degree from true north, Fig. 1). Prior to reconstruction it was one of the arterial roads in the city of Leipzig with a daily traffic volume of around 23000 vehicles on weekdays. Reconstruction began in January 2004. The road was partially closed for this purpose allowing us to investigate the effects of different traffic density. 
The street canyon can be called regular, because the ratio between the height of the five story buildings and width of the street is nearly unity (Vardoulakis et al., 2003). The height of the buildings and the width of the canyon are about $18 \mathrm{~m}$. In such canyons, a flow field with one large recirculation vortex is expected when wind direction is perpendicular to the street and when the wind speed is larger than a lower limit of about two meters per second. Furthermore, the street canyon can be specified as short (Vardoulakis et al., 2003), because an intersection is located about $150 \mathrm{~m}$ from the measurement site. This causes stop and go traffic in front of the measurement site.

\subsection{Instrumentation}

\subsubsection{Traffic counts}

Traffic was detected with an optical system (AutoscopeRackvision Image-Sensing-Systems (ISS), St. Paul, USA, $\mathrm{MN}$ ). Traffic on all four lanes of the street was counted using a single camera. The camera was positioned on the top of a traffic light pylon at the nearby intersection, located about $20 \mathrm{~m}$ from the aerosol inlet. The camera was installed in October 2003. Reconstruction of the road started January 2004. The traffic light pylon with the camera was removed in April 2004.

Automatic traffic counts were validated with several manual counts in October 2003. The inaccuracy in counting passenger cars was about 2.5 percent. The relatively high error of 25 percent for trucks was due to several reasons. First is was necessary to discriminate trucks from trams, which do not emit particles in the considered size range. This differentiation did not work exactly at all times. Another problem was differences in contrast, especially at twilight and at nighttime conditions. Furthermore, the relatively low position of the camera implicated overlapping effects between the lanes during heavy traffic. Errors also caused by abnormal use of the lanes, for example by parking cars.

\subsubsection{Particle size distribution measurements}

The measurement site with the aerosol inlet is located on the north side of the street at the second floor of an five storey apartment house. The height above the sidewalk is approximately five meters.

Particle size distributions were also measured at the Leibniz Institute of Tropospheric Research (IfT), located at a distance of approx two kilometers away (Fig. 1). The measurement site at the IfT is a local but not regional background site. IfT is also influenced by traffic. A large road is about 100 m away.

Particle size distributions are measured using identical TDMPS systems (twin differential mobility particle sizer, TDMPS, Birmili et al., 1999) consisting of two Hauke-type DMAs (differential mobility analyzer). The first DMA is an Ultrafine DMA (UDMA) which selects particles from 3-22 nm in diameter at an aerosol/sheath-air flow rate of $2 / 201 / \mathrm{min}$, and the second DMA selects particles from 22 $800 \mathrm{~nm}$ at an aerosol/sheath-air flow rate of $0.5 / 5 \mathrm{l} / \mathrm{min}$. The relative humidity of the sheath air is stabilized at less than 5 percent. Particles are counted downstream of the DMA using a condensation particle counter (CPC), model TSI 3010 (TSI Inc., St. Paul, MN), and downstream of the UDMA using an Ultrafine CPC, model TSI 3025 (TSI Inc., St. Paul, MN). Custom software using the measured transfer functions of the DMAs is used for the inversion of the raw mobility distributions (Stratmann and Wiedensohler, 1996). The TDMPS system measures a complete particle size distribution (40 channels, 3-800 nm) every $10 \mathrm{~min}$.

\subsubsection{Meteorology data}

Meteorological parameters were measured at the IfT at the same time. These measurements were made above general roof level at a height of $16 \mathrm{~m}$. In this study, wind speed and direction (Metek USA1, Elmshorn, Germany), air pressure (Vaisala PTB220, Helsinki Finnland), temperature (Thiess, model PT100, Goettingen, Germany), relative humidity (Vaisala HMP243, Helsinki, Finnland) and global radiation (Kipp and Zonen CM11, Delft, NL) were used for investigations.

Wind data were also measured with ultrasonic anemometers in the Eisenbahnstrasse (Gill R2, Gill Instruments, Hampshire, England). One anemometer was positioned on the top of the five storey apartment house with the station in the street canyon in December 2003 and another one was positioned next to the aerosol inlet in June and July 2004. Because horizontal wind measurements at the Eisenbahnstrasse started December 2003, data from the IfT were used for investigations in this study. Wind direction between the two sites was in good agreement, whereas measured wind speed slightly differed. Therefore, wind speed data were only categorized into two cases $\left(>1.5 \mathrm{~ms}^{-1}\right.$ and $\leq 1.5 \mathrm{~ms}^{-1}$ ) for correlation analysis.

\subsection{Data analysis}

The data were available with different temporal resolutions. From all data, hourly values were calculated for investigations in this study.

In order to identify meteorological parameters that could have influenced the particle size distribution, a multiple regression was calculated using hourly data and integrated particle number concentration. Calculations were made using SPSS11 (SPSS base 11.0, SPSS Inc., Chicago, IL).

Measurements of vertical wind speed inside the street canyon as well as traffic were conducted at different times. Vertical wind speed was measured in June and July 2004. Traffic counts were already finished at that time, because the camera was dismounted during road restructuring. 


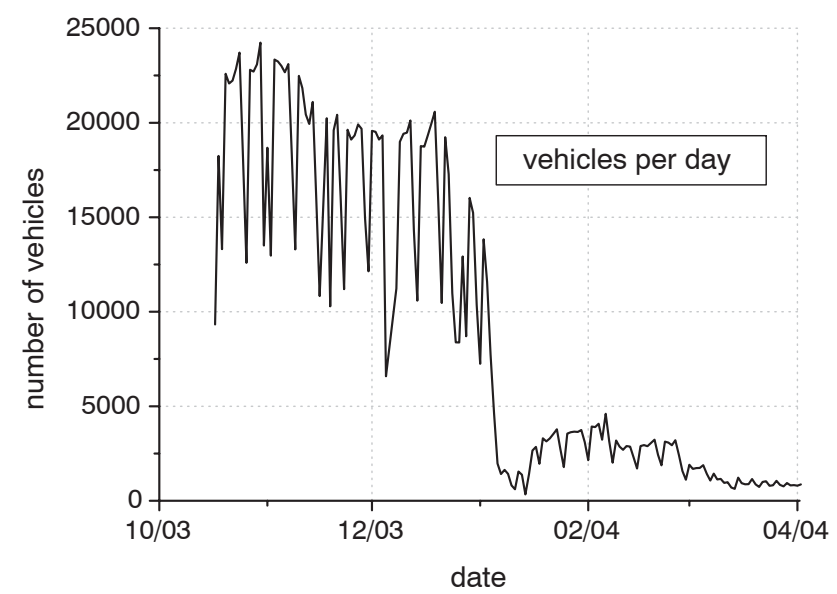

Fig. 2. Time series of the traffic volume during the measurement campaign from October 2003 through March 2004.

Furthermore, only one measurement site inside the canyon was used, which is not enough to characterize the whole flow field. Because the Eisenbahnstrasse is a regular street canyon with a very typical behavior, a simplified fluid dynamics model (CFD model) was used to generalize the wind measurements calculating the flow field inside the canyon. Correlation between measurements and modeling results were about 0.95 . Thus, the calculations established the connection between horizontal roof level wind and the flow field inside the canyon (Voigtländer, 2005). The typical circulation in a regular street canyon can be found in literature (e.g., Scaperdas and Colville, 1998; Assimakopoulos et al., 2003; Nazridoust and Ahmadi, 2006). Traffic exhaust from street is directly transported to the lee side building of the street canyon.

\section{Results and Discussion}

\subsection{General remarks}

During the measurement campaign, the Eisenbahnstrasse was closed for reconstructing. The correlation analysis presented in this study focussed on the time period before the road was closed. Data measured during the reconstruction were added to show the reduction in the measured parameters and to support the analysis. Analysis due to wind direction were performed with regard to orientation (about 285 degree) of the Eisenbahnstrasse. In this work, term 'north' were used for 15 degree and term 'south' for 195 degree. Investigations were performed on an hourly basis.

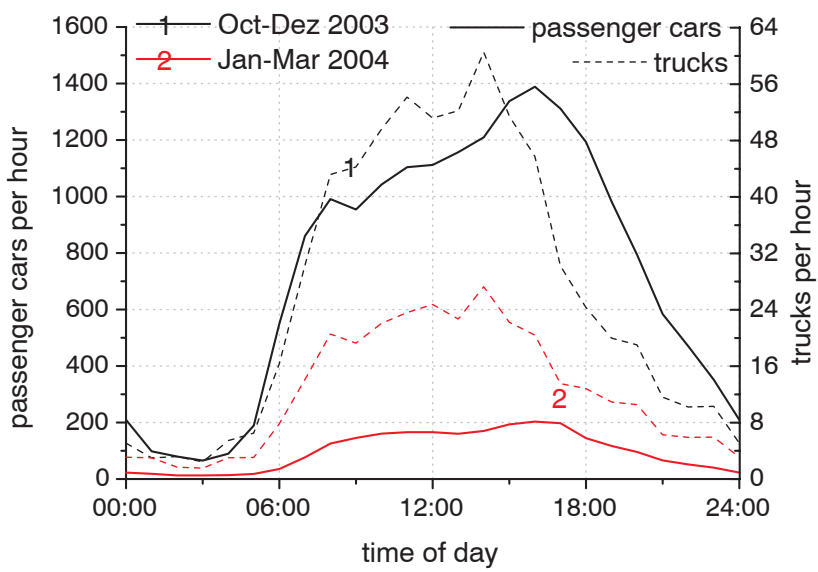

Fig. 3. Mean daily time series of traffic volume for passenger cars and trucks on weekdays.

\subsection{Traffic counts}

Measured traffic volume from October 2003 through March 2004 is shown in Fig. 2. At the beginning of the experiment in October 2003 the traffic volume was above 20000 vehicles per weekday. In November 2003 a bypass road was opened and a weak reduction of traffic volume was therefore observed. Before reconstruction, the fraction of trucks was between 3 and 4 percent on weekdays.

With the beginning of reconstruction in January 2004, the road was partial closed. Therefore, traffic was reduced to approximately 3000 cars per day. In April 2004, the Eisenbahnstrasse was completely closed near the measurement site and the traffic light pylon with the camera was dismounted.

On weekdays, the traffic volume was significantly higher than during weekends. The lowest traffic volume was observed on Sundays. On weekdays, two maxima were observed, which occurred during the rush hours around $08.00 \mathrm{~h}$ in the morning and $16.00 \mathrm{~h}$ in the afternoon. The daily minimum was around $03.00 \mathrm{~h}$ at night (Fig. 3).

\subsection{Integral particle number concentration}

Figure 4 shows the time series of the daily means of the total particle number concentration in the size range between 3 to $800 \mathrm{~nm}$ during the measurement campaign from October 2003 through March 2004.

Similar to the diurnal variation of the traffic volume (Fig. 3), maxima of particle number concentrations were observed on weekdays and during the rush hours, minima on weekends and at nighttime. In Fig. 5, particle number concentration and number of passenger cars on weekdays from October to through December 2003 are compared. Our measurements agrees well with other studies (e.g., Hussein et al., 


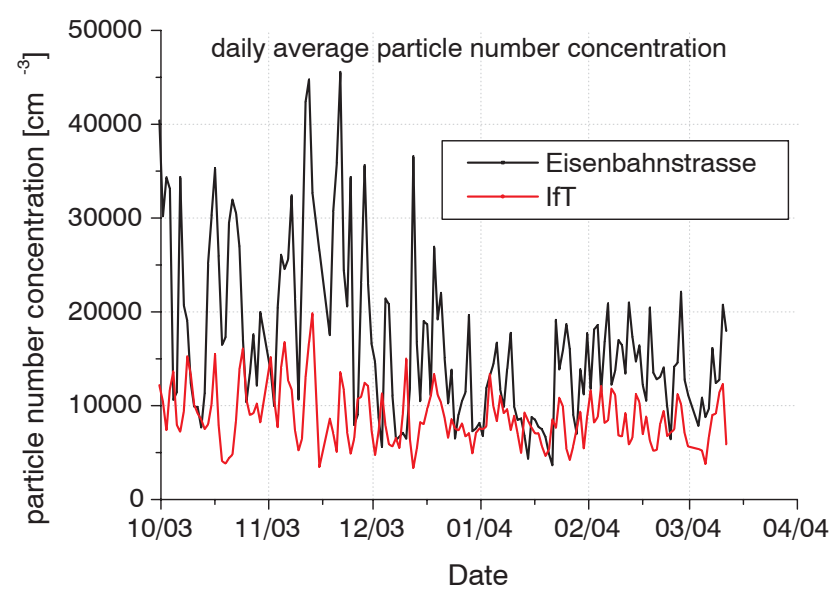

Fig. 4. Time series of daily mean integrated particle number concentration in the range from 3 to $800 \mathrm{~nm}$ from October 2003 through March 2004.

2004; Virtanen et al., 2006). Therefore, our investigations are exemplary for many other similar street canyons. The daily pattern of the particle number concentration is characterized by two peaks. Lowest total particle number concentrations and traffic volumes were observed about 03:00 in the morning (UTC). Maximum particle concentrations occurred about 09:00 in the morning (UTC), while the maximum traffic density was measured in the afternoon. Virtanen et al. (2006) observed the same effect and explained it with reduced vertical mixing in winter mornings. Additionally, traffic volume was unequal distributed in our experiment. In the morning, more passenger cars towards the city (on the side of the aerosol inlet) were detected. In the afternoon, it was reversed. Thus, we explain the higher peak in the morning also with higher traffic emissions next to the inlet.

The reduced traffic volume after the beginning of road reconstruction in January 2004 led to a reduced particle number concentration. From January to through March 2004 the reduction in total particle number concentration was about 50 percent on weekdays compared with the period from October to through December 2003 (from about $20000 \mathrm{~cm}^{-3}$ Oct-Dec 2003 to about $11000 \mathrm{~cm}^{-3}$ Jan-Mar 2004).

Correlation coefficients between aerosol number concentrations and traffic were calculated. With no regard to meteorological and other parameters, correlations were weak. Using total particle number concentration and all wind directions, a correlation coefficient less than 0.5 was obtained for the time period from October 2003 to through March 2004. The value was the almost exactly same using only the time period with full traffic from October through December 2003. Considering only the measurements during road restructuring with reduced traffic volume, the correlation coefficient was only about 0.3 . The calculated correlation co-

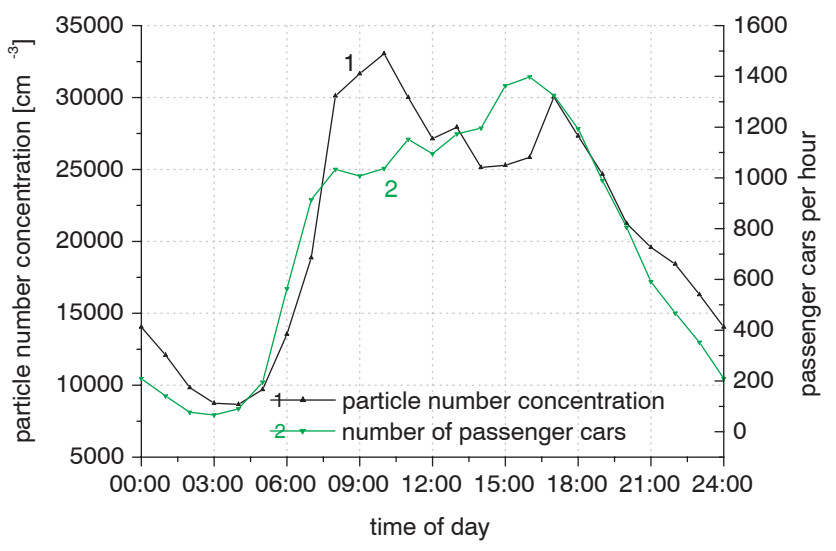

Fig. 5. Time series of the daily mean total particle number concentration and traffic volume at weekdays from October through December 2003.

efficient is similar to previous studies (e.g., Harrison et al., 2000). In contrast to other studies (e.g., Charron and Harrison, 2003) no significant differences were found between passenger cars and trucks in our measurements. The reasons were different. At first the error counting trucks was relatively high and about 25 percent, compared to manual measurements. The reasons for the detection error were given above. Additionally, passenger cars and truck traffic densities were highly correlated $(>0.8)$ at our site on weekdays and the fraction of trucks was only about 3-4 percent. In combination, we were not able the separate our signal significantly. Differences between the correlation coefficients were within this uncertainty and are therefore not represented separately in this study.

\subsection{Regression analysis}

Correlation coefficients between total particle number concentration and traffic volume are relatively weak. A multiple regression was calculated to identify meteorological parameters that could have influenced the particle size distribution. Horizontal wind data, temperature, pressure, relative humidity and global radiation were included in the analysis. Due to its discontinuity at north $(360=0)$, wind direction cannot be used in a linear regression directly, but has to split up with trigonometrical functions. Wind data have to be used in form of wind vectors. In this study, the transformation of the wind data was made due to the orientation of the Eisenbahnstrasse (285 degree from true north).

The linear regression in this study was performed with regard to the measured total particle number concentration. This means, only parameters which influences particle number concentration could be identified with the regression analysis. A shift of the maximum in the particle size 
Table 1. Conclusion of the multiple regression using (a) wind vectors, (b) like (a) but excluding high values of global radiation (greater than $300 \mathrm{Wm}^{-2}$, (c) like (a) but excluding high values of relative humidity (greater than 98 percent). The short cuts mean: cars - number of cars, $\boldsymbol{V}$ - wind vector perpendicular to street, $R$ - global radiation, $R H$ - relative humidity, $p$ - air pressure, $T-$ temperature.

\begin{tabular}{llccc}
\hline \multicolumn{4}{c}{ multiple regression } \\
\hline \multicolumn{1}{c}{ model } & $R$ & $R^{2}$ & $\Delta R^{2}$ \\
\hline (a) & cars & 0.601 & 0.361 & 0.361 \\
& cars, $\boldsymbol{V}$ & 0.640 & 0.409 & 0.048 \\
& cars, $\boldsymbol{V}, R$ & 0.648 & 0.419 & 0.010 \\
& cars, $\boldsymbol{V}, R, R H$ & 0.660 & 0.435 & 0.016 \\
& cars, $\boldsymbol{V}, R, R H, T$ & 0.666 & 0.443 & 0.008 \\
& cars, $\boldsymbol{V}, R, R H, T, p$ & 0.671 & 0.449 & 0.006 \\
\hline (b) & cars & 0.613 & 0.375 & 0.375 \\
& cars, $\boldsymbol{V}$ & 0.655 & 0.429 & 0.054 \\
& cars, $\boldsymbol{V}, R H$ & 0.667 & 0.445 & 0.016 \\
& cars, $\boldsymbol{V}, R H, T$ & 0.673 & 0.453 & 0.008 \\
& cars, $\boldsymbol{V}, R H, T, p$ & 0.678 & 0.459 & 0.006 \\
& cars, $\boldsymbol{V}, R H, T, p, R$ & 0.681 & 0.463 & 0.004 \\
\hline (c) & cars & 0.592 & 0.350 & 0.350 \\
& cars, $\boldsymbol{V}$ & 0.631 & 0.397 & 0.047 \\
& cars, $\boldsymbol{V}, T$ & 0.639 & 0.408 & 0.011 \\
& cars, $\boldsymbol{V}, T, p$ & 0.646 & 0.417 & 0.009 \\
& cars, $\boldsymbol{V}, T, p, R H$ & 0.647 & 0.418 & 0.001 \\
\hline
\end{tabular}

distribution without altering the total particle number concentration is not shown by this analysis and further investigations are necessary.

The results of the analysis are represented in Table 1 . Therein, the used variables, the correlation coefficient between regression model and integrated particle number concentration $(R)$ and the variance $\left(R^{2}\right)$ are shown. The results show that traffic explained more then one third of the variance of the integrated particle number concentration in the considered size range. Next to traffic, wind parameters showed the strongest influence on particle number concentrations. This agrees very well with other studies (e.g., Ketzel et al., 2002). Next, solar radiation, temperature and relative humidity influences the measured aerosol (Table 1a). Linear regression was performed again, but excluding high values for solar radiation and relative humidity. Limits of $300 \mathrm{Wm}^{-2}$ for solar radiation and 98 percent for relative humidity were used. High values of solar radiation may cause particle nucleation events, which should be excluded. Furthermore, only few valid data were available. Less than 3 percent of all data were above the chosen limit. Measurements above 98 percent of relative humidity were neglected, because measurement accuracy is weak and again, only less than 3 percent of all data were above this limit. On the other
Table 2. Mean total particle number concentration and mean particle volume in the Eisenbahnstrasse (Ei) and the IfT, calculated from hourly data and separated to weekdays and weekends and to wind direction.

\begin{tabular}{|c|c|c|c|}
\hline \multicolumn{4}{|c|}{ mean particle values (Oct-Dec 03) } \\
\hline station & $\begin{array}{c}\text { valid } \\
\text { hourly data }\end{array}$ & $\frac{\mathrm{N}}{\left[1 / \mathrm{cm}^{-3}\right]}$ & $\begin{array}{c}\mathrm{V} \\
{\left[\mu \mathrm{m}^{3} / \mathrm{cm}^{-3}\right]}\end{array}$ \\
\hline \multicolumn{4}{|c|}{ all cases } \\
\hline $\mathrm{Ei}$ & 1485 & 17119 & 17.2 \\
\hline IfT & & 9683 & \\
\hline \multicolumn{4}{|c|}{ weekdays } \\
\hline $\mathrm{Ei}$ & 1050 & 20343 & 19.4 \\
\hline IfT & & 10763 & \\
\hline \multicolumn{4}{|c|}{ weekdays, northerly wind $\left(330^{\circ}-60^{\circ}\right)$} \\
\hline $\mathrm{Ei}$ & 170 & 26135 & 27.2 \\
\hline IfT & & 8793 & \\
\hline \multicolumn{4}{|c|}{ weekdays, southerly wind $\left(150^{\circ}-240^{\circ}\right)$} \\
\hline $\mathrm{Ei}$ & 470 & 14543 & 15.2 \\
\hline IfT & & 11312 & \\
\hline \multicolumn{4}{|c|}{ northerly wind $\left(330^{\circ}-60^{\circ}\right)$} \\
\hline $\mathrm{Ei}$ & 198 & 25166 & 26.4 \\
\hline IfT & & 8212 & \\
\hline \multicolumn{4}{|c|}{ southerly wind $\left(150^{\circ}-240^{\circ}\right)$} \\
\hline $\mathrm{Ei}$ & 750 & 11771 & 13.1 \\
\hline IfT & & 9803 & \\
\hline
\end{tabular}

hand, aerosol droplets size is highly dependent on small variations of $R H$ in this range. The results are shown in Table $1 \mathrm{~b}$ and c. Therein, the influence of both gets negligible.

The influence of temperature was tested. Other studies observed a seasonal (e.g., Hussein et al., 2004) or temperature (e.g., Hussein et al., 2006) dependency of the measured particle size distribution with higher concentrations in winter especially for the nucleation mode particles (Virtanen et al., 2006). Generally and in agreement with Virtanen et al. (2006), we observed higher particle number concentrations during lower temperatures. But in our experiment, cases with low temperatures were often connected with northerly wind conditions (below $0^{\circ} \mathrm{C}$ : 25 percent, above $6^{\circ} \mathrm{C}$ : 7 percent). Thus, the temperature dependency of particle number concentration can be explained by the help of wind parameter. Additionally, the particle mean size distribution for different ranges of temperature was analyzed. In our data, no shift could be observed.

Mean particle size distributions for different size ranges of $R H$ were analyzed. Again, no shift in particle size 

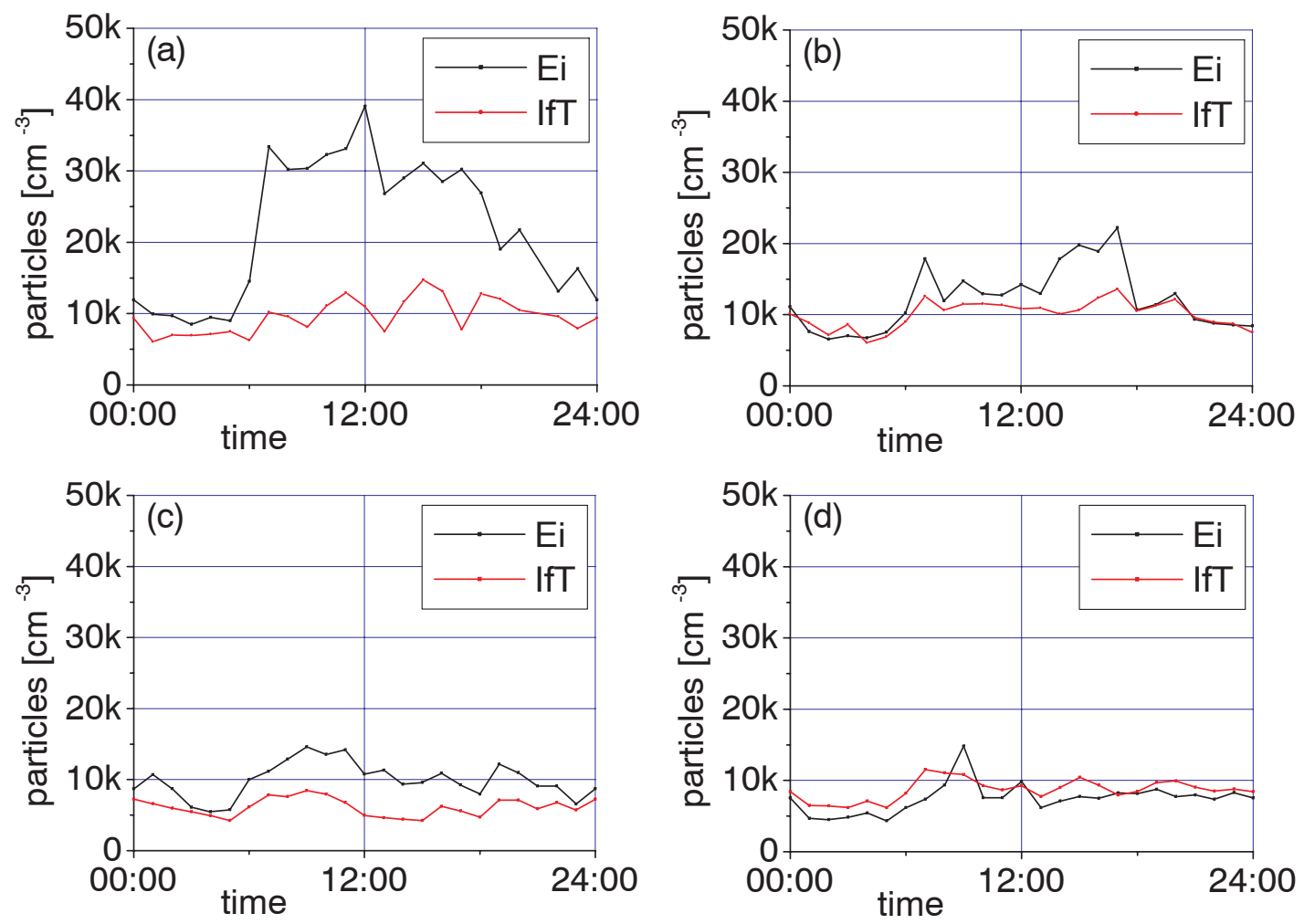

Fig. 6. Mean diurnal variability of the integrated particle number concentration in the Eisenbahnstrasse (Ei) in the range between 3 to $800 \mathrm{~nm}$ at weekdays from October 2003 through March 2004. The data set was separated into the time period before (a) and (b) and after (c) and (d) the beginning of road constructering and in cases with northerly wind (perpendicular to the street, with the measuring site in the lee (a) and (c)) and south wind (perpendicular to the street, with the measuring site in the luff (b) and (d)). For additional information we included measurements from the IfT.

distribution was observed. The growth factor of traffic caused soot particles is low below the chosen limit of 98 percent $R H$ (clearly below 1.05, Weingartner et al., 1997) and the number fraction of less soluble soot particles in street canyons is high and about 50 percent in the 60 to $80 \mathrm{~nm}$ size bin (Rose et al., 2006). The influence of $R H$ on the particle size distribution can be therefore neglected in our study.

Note, that this study includes only measurements during winter. No statements about seasonal variability can be made. The considered time period also explains the small range in meteorological parameters (temperature, $R H$ ).

As result of the linear regression analysis, other parameters than number of cars and wind vector have only negligible influence on correlation coefficients between cars and meteorology. We have therefore only used wind parameters for further analysis.

The data set was divided according to wind speed. Data were separated into cases with wind speed above $1.5 \mathrm{~ms}^{-1}$ and cases below this limit, because the typical large eddy (which is influencing dilution and dispersion) inside of a canyon does not develop below a certain synoptic wind speed. Cases with lower wind speed were associated with slightly lower correlation coefficients (of traffic and particle size distribution) than cases with higher wind speed (0.49 vs. 0.51 , integrated particles number concentration). Because differences were low, the results are not presented here separately.

The data were also segregated according to different sectors of horizontal wind direction. In order to have sufficient data in each sector, a sector width of 30 degrees were used. 360 of these sectors with an increment of one degree horizontal wind direction were accumulated.

Calculated correlations strongly depend on wind direction. For luff side conditions (southerly wind) low correlations about 0.4 were calculated, whereas lee side conditions (northerly wind) led to high correlation coefficients over 0.7 . In a regular street canyon, traffic emissions are transported to the lee of the street. In the luff, only the recirculated aerosol is observed. Our results agree well with further investigations about street canyons (e.g., Vardoulakis et al., 2003).

With regard to the flow field inside the canyon, integrated mean particle number concentrations for different wind directions are shown in Fig. 6. The data were averaged over all days of the measurement campaign. For addi- 

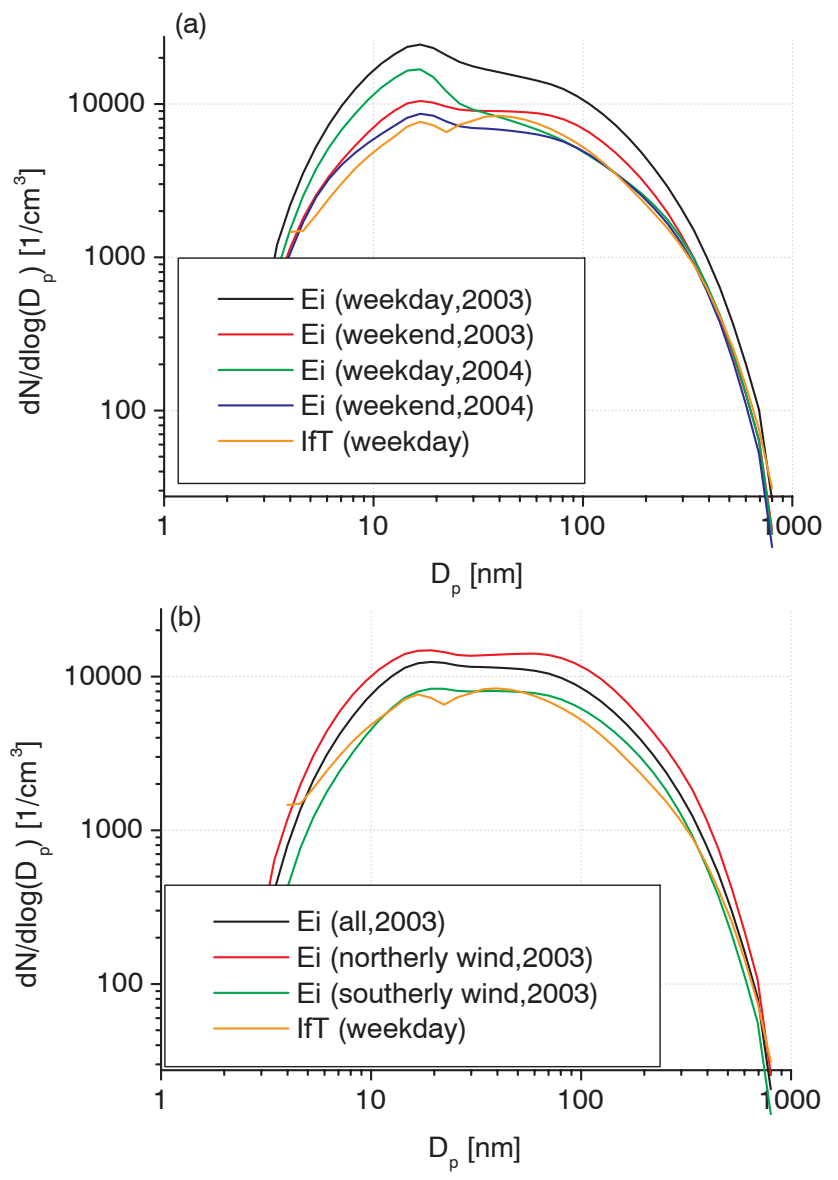

Fig. 7. Mean particle size distribution in the Eisenbahnstrasse (Ei) compared to IfT in the size range between 3 to $800 \mathrm{~nm}$ separated due to weekdays/weekends (a), the time period before and during road restructuring (a) and to wind direction (b).

tional information, the averaged particle number concentrations measured at the IfT are also shown in these figures to demonstrate the differences between two sites located only $1.5 \mathrm{~km}$ apart (Tuch et al., 2006). Concentrations found in the luff (Fig. 6b and d) where significant lower than those at the lee side building (northerly wind, Fig. $6 a+c$ ) and in the size range of the concentration measured at the IfT see also Table 2) with different mean values of the integrated total particle number concentration. In cases of southerly wind (luff side), urban air was transported to the aerosol inlet with the large vortex in the canyon. Otherwise, during northerly wind, aerosol from street was transported directly to the inlet.

\subsection{Number size distribution}

Mean particle number size distribution on weekdays (Monday-Friday), weekends and during the time period of the road reconstruction are shown in Fig. 7 a. Two maxima for particles in the nucleation mode with diameters of about $13 \mathrm{~nm}$ and in the Aitken mode between 60 to $80 \mathrm{~nm}$

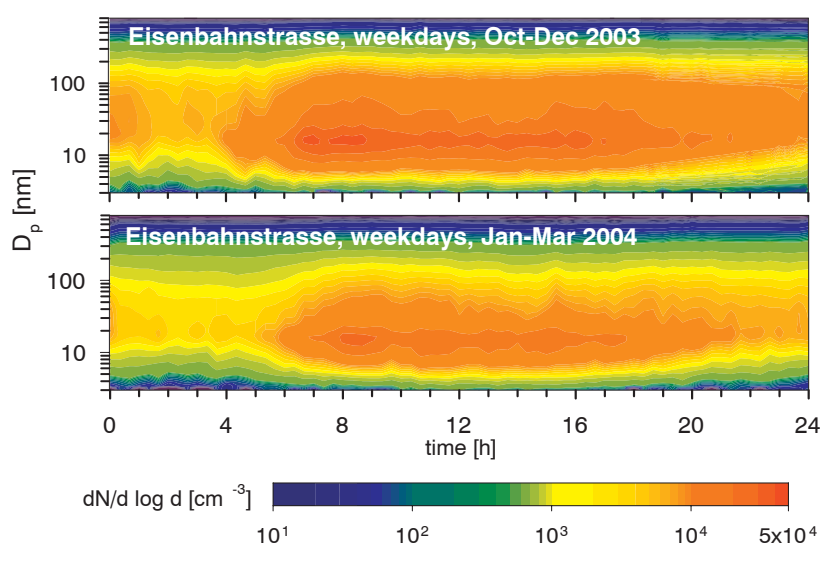

Fig. 8. Diurnal variability of the mean particle size distribution at weekdays in the Eisenbahnstrasse in the range between 3 to $800 \mathrm{~nm}$.

in diameter are visible. These maxima may be attributed to traffic. They are in good agreement with previous studies (e.g., Kittelson et al., 2000). Both prior to reconstruction and during partial closure of the Eisenbahnstrasse number concentrations measured on weekends were lower compared to those measured during the week. These results reflect the direct influence of local traffic at Eisenbahnstrasse. Number size distributions measured at the IfT are, on the other hand, lower during the whole study period supporting the definition of this site as an urban background station. It needs, however to be noted, that Fig. 6 clearly shows a diurnal variability of the integral particle number concentrations at the IfT which is due to traffic in the vicinity of this site. Figure $7 \mathrm{~b}$ demonstrates the influence of wind direction on the measured number size distribution during the time period prior to road reconstruction. The red line represents number size distributions measured during time periods with wind from northern directions. During such situations concentrations are significantly higher compared to those measured at winds from the south (green line). This graph emphasizes that concentrations measured in a street canyon are severely influenced by the local flow field in a street canyon induced by the wind over the roof top.

Integral values of particle number concentrations and volume concentrations prior to the road closure are summarized in Table 2. Both integral particle number concentrations and volume concentrations differ by a factor of two depending on the wind direction. This difference exceeds the difference observed between weekdays and weekends. Table 2 suggests that a street canyon site may not even be suitable to measure integral parameters of the urban aerosol representative for a whole city.

Figure 8 shows the diurnal variability of the number size distributions on weekdays both prior to and during road closure. Notably concentrations during road closure are still 
relatively high. This is probably due to the use of heavy duty machines used for roadwork and due to the incomplete closure of the street. The delayed onset of the morning traffic peak of the number size distributions during road closure supports this hypothesis.

Spearman correlation coefficients between particle size distributions and traffic volume were calculated. The results are shown in Fig. 9. The correlation coefficients are strongly size and wind direction dependent. Two extreme cases for wind perpendicular to the street are shown.

Correlation coefficients including all wind directions (black curve) agree well with cases of southerly wind direction, because the main wind direction at the measurement site is south-west (Fig. 1). Correlation coefficients up to about 0.8 were found for northerly wind directions (aerosol inlet in the lee side of the street) in the size range from 10-100 nm size. Values in this size range are nearly constant. Southerly wind (luff side) yielded, however, lower correlation coefficients of maximal 0.6 in all size ranges (Fig. 9).

The maximum of correlation coefficients calculated for northerly wind directions (red curve) is shifted towards larger particles for southerly wind (green curve). This shift can be explained by circulation conditions inside the street canyon. With wind from the south our site is located in the luff. Under these conditions aerosol originating from local traffic is not directly transported to the inlet. Only the recirculated fraction of the aerosol from local traffic reached our instruments. Transport time to the inlet and dilution by urban background aerosol were increased under these conditions. The longer time to reach the inlet is comparable to a longer travel distance to the measurement point from the particle source. Thus, our results agree with other studies, observing a strong decrease of the nucleation mode peak with increasing distance to the road (Zhu and Hinds, 2002).

In the urban atmosphere particles smaller than $10 \mathrm{~nm}$ in diameter are rapidly removed by coagulation. Therefore correlation coefficients decrease for these particles with longer transport time to the inlet.

With the relatively long lifetimes of particles with sizes between 10 and $30 \mathrm{~nm}$ both traffic in the street canyon and urban background aerosol contribute to the peak of the green and black curve.

We observed the largest differences of correlation coefficients for the size range from 30 to $10 \mathrm{~nm}$. For southerly wind, correlation coefficients decreased to 0.3 with increasing particle diameter whereas correlation coefficients for northerly wind remain unchanged. Particles in this size range originate both from local source and urban background (Birmili et al., 2001).

Figure 9 also demonstrates, that particles larger than about $300 \mathrm{~nm}$ in diameter cannot be attributed to traffic. These particles originate mainly from regional and urban background (Birmili et al., 2001).

Subtraction of background aerosol concentrations measured at the IfT did not yield significantly higher correlation

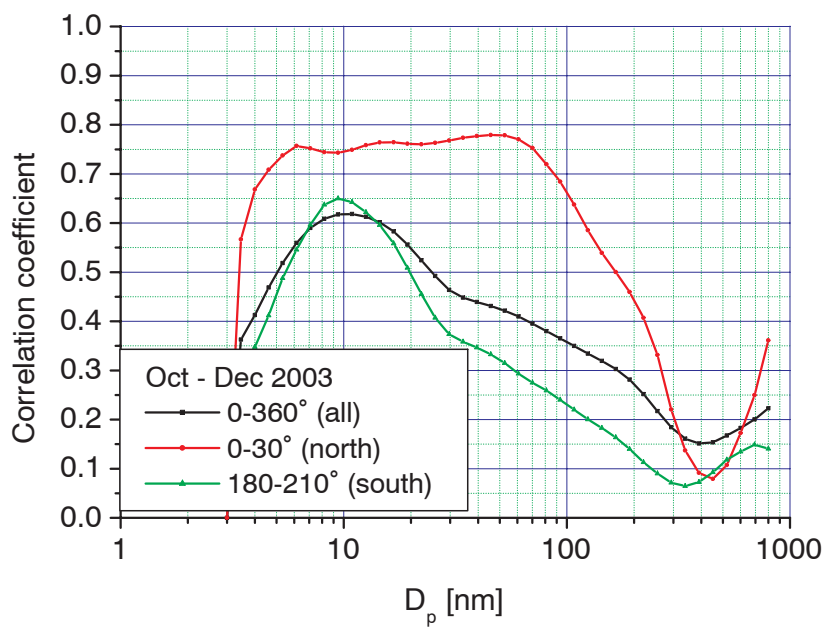

Fig. 9. Correlation between passenger cars and particle number size distribution for all days from October 2003 to December 2003. The results are plotted for different wind directions due to the orientation of the Eisenbahnstrasse and with no regard to wind velocity. For northerly wind data with 0 to 30 degree horizontal wind direction were used, for southerly wind data with 180 to 210 degree.

coefficients. The biggest increase was found for $20 \mathrm{~nm}$ particles and northerly wind directions ( 0.75 to 0.85$)$. This weak increase is primarily due to the fact that IfT is influenced by local traffic. There was no increase for southerly wind because both IfT and Eisenbahnstrasse are influenced by urban background aerosol concentrations under these conditions.

Figure 10 summarizes our results. It shows a combination of vertical wind speed (=measure for the large eddy in the street canyon) and size dependent correlation coefficients between traffic densities and particle number concentrations depending on horizontal wind direction.

We have included measurements of the horizontal wind speed measured at the inlet and calculated horizontal wind speeds from our simple fluid dynamic model for our measurement site. Correlations coefficients were calculated for wind direction sectors of 30 degree. Our findings show a good agreement of measured vertical wind speed (black line) with modelled vertical wind velocities (red line). Both, measurements and modelling results show, that the transport of traffic exhaust to the measurement site depends on wind direction. Therefore, correlation coefficients between traffic volume and particle concentration in size bins can only be high, if wind directions is perpendicular to the street canyon and northerly wind directions (300 to 45 degree). Correlation coefficients are lower for wind directions parallel to the street canyon. Lowest correlation coefficients were observed for southerly wind directions. These findings are in good agreement with fluid dynamics in street canyons. Our measurements of the dependence of particle size distribution 


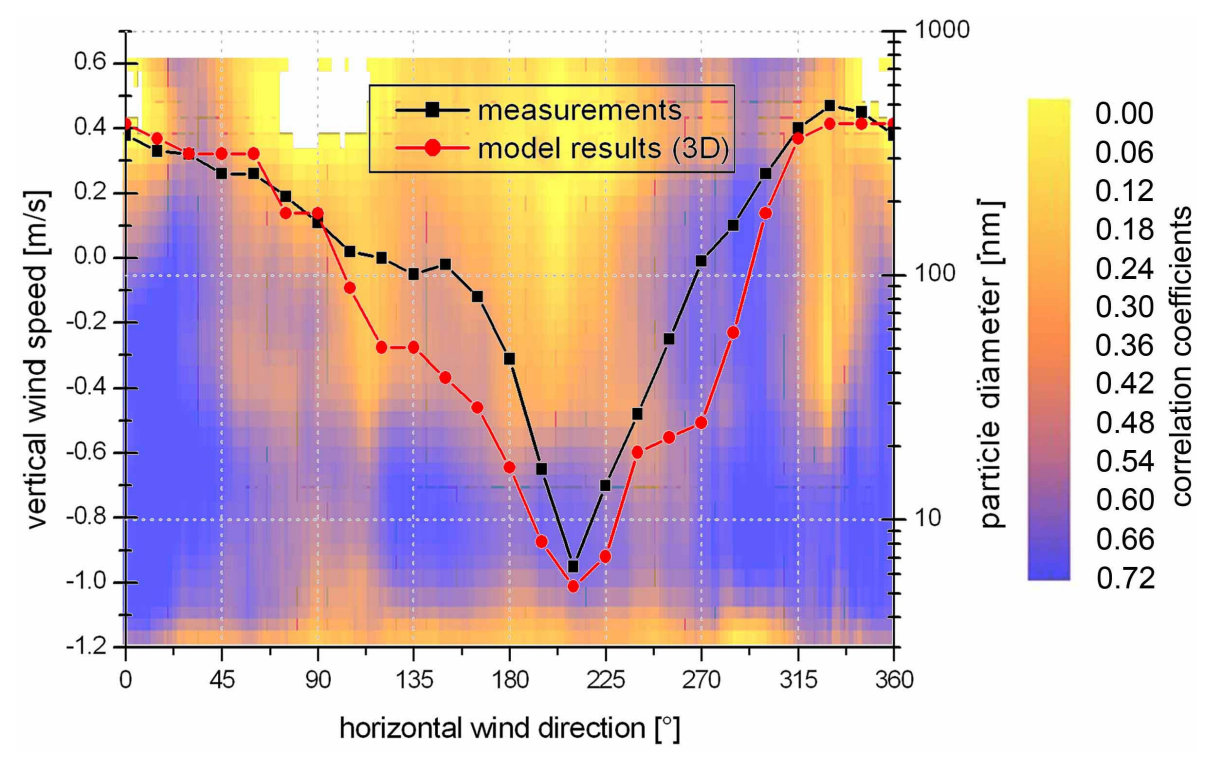

Fig. 10. Comparison of measured and modeled vertical wind speed with correlations between traffic volume and particle number size distribution dependent on the horizontally wind direction. The given wind direction is valid for the Eisenbahnstrasse, but the results are valid for similar street canyons by transforming the axis. In the Figure, directions of 105 and 285 degree means a wind direction longitudinal to the street.

on wind direction along with the good agreement of vertical wind speed from measurements and modelling suggest that models currently calculating particle number concentrations in street canyons from traffic densities may be extended to calculate number size distributions in the future.

\section{Conclusions}

Atmospheric particle number size distributions in a particle size range between 3 and $800 \mathrm{~nm}$ were measured in a highlytrafficked street canyon in Leipzig, Germany (width: $17 \mathrm{~m}$, height: ca. $18 \mathrm{~m}$ ). The continuous measurements between October 2003 and April 2004 also included real-time traffic volume and locally measured wind parameters. Typical particle concentrations during work days were between 25000 and $35000 \mathrm{~cm}^{-3}$, accompanied by vehicle densities between 1000 and $1300 \mathrm{~h}^{-1}$.

Taking into account all occurring wind directions, only moderate correlations $(<0.5)$ were found between particle number concentration and traffic volume. Considering northerly winds only, i.e., those under which the sampling location was downwind the stream of vehicles, these correlations increased remarkably. Maximum correlation coefficients of about 0.75 were found between traffic volume and the concentration of particles between 10-100 nm. Weaker correlations, however, were found for larger particles $(\sim 0.4$ for $D_{p}>300 \mathrm{~nm}$ ).

The results demonstrate that the influence of the given traffic mix ( 3 percent trucks and busses, about 20 percent fraction of diesel cars in passenger cars) on the urban particle size distribution is size selective with a maximum in the 10 to $100 \mathrm{~nm}$ size bin. Particles above $300 \mathrm{~nm}$ could not be associated with traffic volume. We observed no conclusive effects of solar radiation, air pressure, ambient temperature and relative humidity on the measured particle concentrations.

The linear correlation analysis suggested that about 60 percent of the variation of the particle number size distribution in the size range between 10 and $100 \mathrm{~nm}$ at the street canyon sampling site originated from traffic under downwind conditions, but less than 20 percent under upwind conditions. This illustrates the importance of the local flow circulation on point measurements in a street canyon, and was verified for the geometry of the given street canyon using a fluid dynamics model.

The investigations in our study show, that traffic and particle size distribution measured at the luff side in a street cannot be connected with each other. On the other hand, the particle size distribution at the lee side is significantly influenced by traffic. We therefore confirm previous findings that the local flow conditions need to be carefully characterized and considered when establishing representative particle number size distributions in a strongly inhomogeneous urban terrain, such as a street canyon.

Our investigations also show, that the influence is limited to particles in the size range smaller than $200 \mathrm{~nm}$ in diameter. Larger particles cannot be connected with traffic, but are part of the background concentration. This means, reduction of $\mathrm{PM}_{10}$ or $\mathrm{PM}_{2.5}$, conducted in many European cities for air quality monitoring, would therefore only be very limited by reducing traffic. 
Edited by: U. Lohmann

\section{References}

Assimakopoulos, V., Simon, H., and Moussiopoulos, N.: A numerical study of atmospheric pollutant dispersion in different twodimensional street canyon configurations, Atmos. Environ., 37, 4037-4049, 2003.

Baik, J.-J. and Kim, J.-J.: On the escape of pollutants from urban street canyons, Atmos. Environ., 36, 527-536, 2002.

Birmili, W., Stratmann, F., and Wiedensohler, A.: Design of a DMA-Based Size Spectrometer for a Large Particle Size Range and Stable Operation, J. Aerosol Sci., 30, 549-553, 1999.

Birmili, W., Wiedensohler, A., Heintzenberg, J., and Lehmann, K.: Atmospheric particle number size distribution in central Europe: statistical relations to air masses and meteorology, J. Geophys. Res., 106(D23), 32 005-32 018, 2001.

Broday, D. M.: Deposition of Ultrafine Particles at Carinal Ridges of the Upper Bronchial Airways, Aerosol Sci. Tech., 38, 9911000, 2004.

Charron, A. and Harrison, R.: Primary particle formation from vehicle emissions during exhaust dilution in the roadside atmosphere, Atmos. Environ., 37, 4109-4119, 2003.

Cheng, X. and Hu, F.: Numerical Studies on Flow Fields Around Buildings in an Urban Street Canyon and Cross-Road, Adv. Atmos. Sci., 22, 290-299, 2004.

DePaul, F. T. and Sheih, C. M.: Measurements of wind velocities in a street canyon, Atmos. Environ., 20, 455-459, 1986.

Dockery, D. W. and Pope, C. A.: Acute respiratory effects of particulate air pollution, Annu. Rev. Pub. Health, 15, 107-132, 1994.

Gidhagen, L., Johansson, C., Langner, J., and Olivares, G.: Simulation of $\mathrm{NO}_{\mathrm{x}}$ and ultrafine particles in a street canyon in Stockholm, Sweden, Atmos. Environ., 38, 2029-2044, 2004.

Harrison, R., Charron, A., Lawrence, R., and Jones, A.: Mass Closure and Source Apportionment Studies of Urban Atmospheric Aerosol, 2000.

Hussein, T., Puustinen, A., Aalto, P., Maekelae, J., Haemeri, K., and Kulmala, M.: Urban aerosol number size distributions, Atmos. Chem. Phys., 4, 391-411, 2004, http://www.atmos-chem-phys.net/4/391/2004/.

Hussein, T., Karppinen, A., Kukkonen, J., Härkonen, J., Aalto, P. P., Hämeri, K., Kerminen, V.-M., and Kulmala, M.: Meteorological dependence of size-fractional number concentrations of urban aerosol particles, Atmos. Environ., 40, 1427-1440, 2006.

Kastner-Klein, P., Fedorovich, E., Ketzel, M., Berkowicz, R., and Brittner, R.: The Modelling of Turbulence from Traffic in Urban Dispersion Models - Part II: Evaluation Against Laboratory and Full-Scale Concentration Measurements in Street Canyons, Environ. Fluid Mechan., 3, 145-172, 2003.

Ketzel, M., Louka, P., Sahm, P., Guilloteau, E., Sini, J.-F., and Moussiopoulos, N.: Intercomparison of numerical urban dispersion models - part II: street canyon in Hannover, Germany, Water, Air, Soil Pollut., 2, 603-613, 2002.

Ketzel, M., Wahlin, P., Kristensson, A., Swietlicki, E., Berkowicz, R., Nielsen, O., and Palmgren, F.: Particle size distribution and particle mass measurements at urban, near-city and rural level in the Copenhagen area and Southern Sweden, Atmos. Chem. Phys., 4, 281-292, 2004, http://www.atmos-chem-phys.net/4/281/2004/.
Kim, J.-J. and Baik, J.-J.: A numerical study of the effects of ambient wind direction on flow and dispersion in urban street canyons using the RNG ka-eps turbulence model, Atmos. Environ., 38, 3039-3048, 2004.

Kittelson, D.: Engines and Nanoparticles: a Review, J. Aerosol Sci., 29, 575-588, 1998.

Kittelson, D., Johnson, J., Watts, W., Wei, Q., Drayton, M., and Paulson, D.: Diesel Aerosol Sampling in the Atmosphere, in: SAE Technical Paper Series, Government/Industry Meeting, Washington, D.C., June 19-21, 2000, Vol. No. 2000-01-2212, 2000.

Kovar-Panskus, A., Sini, J.-F., Syvory, E., Czech, M., Abdelqari, A., Mestrayer, P., and Toy, N.: Influence of geometry on the mean flow within urban street canyons - a comparison of wind tunnel experiments and numerical simulations, Water, Air, Soil Pollut., 2, 365-380, 2002.

Lien, F. S., Yee, E., and Cheng, Y.: Simulation of mean flow and turbulence over a $2 \mathrm{D}$ building array using high-resolution $\mathrm{CFD}$ and a distributed drag force approach, J. Wind Eng. Ind. Aerodyn., 92, 117-158, 2004.

Nazridoust, K. and Ahmadi, G.: Airflow and pollutant transport in street canyons, J. Wind Eng. Ind. Aer., 94, 491-522, 2006.

Oberdoerster, G.: Toxicology of ultrafine particles: in vivo studies., Philosophical Transactions of the Royal Society of London, 358, 2719-2740, 2000.

Oberdoerster, G., Oberdoerster, E., and Oberdoerster, J.: Nanotoxicology: An Emerging Discipline Evolving from Studies of Ultrafine Particles, Environ. Health Perspect., 113, 823-839, 2005.

Osunsanya, T., Prescott, G., and Seaton, A.: Acute respiratory effects of particles: mass or number?, Occup Environ Med, 58, 154-159, 2001.

Penttinen, P., Timonen, K. L., Tiittanen, P., Mirme, A., Ruuskanen, J., and Pekkanen, J.: Ultrafine particles in urban air and respiratory health among adult asthmatics, Europ. Respir. J., 17, 428-435, 2001.

Peters, A., Wichmann, H., Tuch, T., Heinrich, J., and Heyder, J.: Respiratory effects are associated with the number of ultrafine particles, Am. J. Respir. Crit. Care Med., 155, 1376-1383, 1997.

Pope, C., Dockery, D., and Schwartz, J.: Review of epidemiological evidence of health effects of particulate air pollution, Toxicol., 7, 1-18, 1995.

Pope, C., Burnett, R., Thun, M., Calle, E., Krewski, D., Ito, K., and Thurston, G.: Lung cancer, cardio-pulmonary mortality, and long-term exposure to fine particulate air pollution, J. Am. Med. Assoc., 287, 1132-1141, 2002.

Rose, D., Wehner, B., Engler, C., Voigtlaender, J., Tuch, T., and Wiedensohler, A.: Atmospheric number size distributions of soot particles and estimation of emission factors, Atmos. Chem. Phys., 6, 1021-1031, 2006, http://www.atmos-chem-phys.net/6/1021/2006/.

Scaperdas, A. and Colville, R.: Assessing the representativeness of monitoring data from an urban intersection site in central London, UK, Atmos. Environ., 33, 661-674, 1998.

Sini, J.-F., Anquetin, S., and Mestayer, P.: Pollutant dispersion and thermal effects in urban street canyons., Atmos. Environ., 30, 2659-2677, 1996.

Stratmann, F. and Wiedensohler, A.: A new data inversion algorithm for DMPS-measurements. European Aerosol Conference, Delft, J. Aerosol Sci., 27, 1, 339-340, 1996. 
Tuch, T., Herbarth, O., Franck, U., Peters, A., Wehner, B., Wiedensohler, A., and Heintzenberg, J.: Weak correlation of ultrafine aerosol particle concentrations $<800 \mathrm{~nm}$ between two sites within one city, J. Exp. Sci. Env., online publication 25 January 2006, doi:10.1038/sj.jes.7500 469, 2006.

Vardoulakis, S., Fisher, B., Pericleous, K., and Gonzalez-Flesca, N.: Modelling air quality in street canyons: a review, Atmos. Environ., 37, 155-182, 2003.

Virtanen, A., Ronkkoe, T., Kannosto, J., Ristimaeki, J., Maekelae, J., Keskinen, J., Pakkanen, T., Hillamo, R., Pirjola, L., and Haemeri, K.: Winter and Summer time size distributions and densities of traffic-related aerosol particles at a busy highway in Helsinki, Atmos. Chem. Phys., 6, 2411-2421, 2006, http://www.atmos-chem-phys.net/6/2411/2006/.

Voigtländer, J.: Abschaetzung des Verkehrseinflusses auf die Partikelgroessenverteilung in einer Strassenschlucht unter Beruecksichtigung meteorologischer Parameter, Master's thesis, University Leipzig, 2005.
Weingartner, E., Burtscher, H., and Spaltenberger, U.: Hygroscopic properties of carbon and diesel soot particles, Atmos. Environ., 31, 2311-2327, 1997.

WHO: Air quality guidelines for Europe, Tech. Rep. 91, World Health Organisation, Copenhagen, Daenemark, http://www.euro. who.int/document/e71922.pdf, 2. Edition, 2000.

Xie, X., Huang, Z., and Wang, J.: Impact of building configuration on air quality in street canyon, Atmos. Environ., 39, 4519-4530, 2005.

Zhang, K. and Wexler, A.: Evolution of particle number distribution near roadways - Part I: analysis of aerosol dynamics and its implications for engine emission measurement, Atmos. Environ., 38, 6643-6653, 2004.

Zhu, Y. and Hinds, W.: Concentration and Size Distribution of Ultrafine Particles Near a Major Highway, Air \& Waste Management Association, 52, 1032-1042, 2002. 